\title{
Manfaat Intervensi Dini Anak Usia 6-12 Bulan dengan Kecurigaan Penyimpangan Perkembangan
}

\author{
Anne Susanty, ${ }^{1}$ Eddy Fadlyana, ${ }^{2}$ Heda Melinda Nataprawira ${ }^{2}$ \\ ${ }^{1}$ Rumah Sakit Pusat Mata Cicendo Bandung ${ }^{2}$ Departemen Ilmu Kesehatan Anak Fakultas Kedokteran \\ Universitas Padjadjaran/Rumah Sakit Dr. Hasan Sadikin Bandung
}

\begin{abstract}
Abstrak
Penyimpangan perkembangan masih merupakan masalah bagi anak di Indonesia. Untuk meminimalkan penyimpangan perkembangan yang dicurigai maka intervensi perkembangan secara dini dapat dilakukan sebagai upaya untuk merangsang berbagai aspek perkembangan. Tujuan penelitian untuk mengetahui manfaat intervensi perkembangan secara dini terhadap anak usia 6-12 bulan yang mengalami kecurigaan penyimpangan perkembangan. Penelitian intervensi tes pra dan pasca dilakukan selama bulan Januari-Maret 2011. Subjek adalah anak sehat usia 6-12 bulan di kelurahan Cibangkong dan Kebongedang Kiaracondong, Bandung. Penapisan perkembangan anak dilakukan dengan menggunakan kuesioner praskrining perkembangan (KPSP) dengan interpretasi hasil sesuai, meragukan, dan penyimpangan. Apabila didapatkan hasil yang meragukan maka orangtua diajarkan melakukan intervensi setiap hari di rumah selama 2 minggu dengan pemantauan setiap 2 hari dengan menggunakan kartu harian. Apabila masih terdapat hasil meragukan pada pascaintervensi, maka dilakukan intervensi ulang selama 2 minggu dengan pengawasan seperti sebelumnya. Analisis perbedaan pra dan pascaintervensi dini dilakukan dengan Tes Cochran. Dari 242 anak sehat yang diperiksa terdapat 208 (86,0\%) anak dengan perkembangan sesuai, $33(13,6 \%)$ anak perkembangan meragukan, dan $1(0,4 \%)$ anak mengalami penyimpangan perkembangan. Drop out terjadi pada 1 dari 33 anak karena dirawat di rumah sakit. Setelah intervensi kecurigaan penyimpangan perkembangan turun menjadi 12/32 setelah 2 minggu, dan 4/32 pada akhir intervensi $(p<0,001)$. Simpulan: terdapat manfaat intervensi dini anak usia 6-12 bulan yang mengalami kecurigaan penyimpangan perkembangan. [MKB. 2014;46(2):63-7]
\end{abstract}

Kata kunci: Deteksi dini, kuesioner praskrining perkembangan

\section{Early Intervention Benefits for Children 6-12 Months Old with Suspect Developmental Delay}

\begin{abstract}
Developmental delay is still a main problem for children in Indonesia. Early intervention is an effort to minimize this delay. The aim of this study was to determine the advantages of early intervention in children 6-12 months old who were suspected as experiencing developmental delay. An intervention study with pre and post design was performed on physically healthy children aged 6-12 months in Cibangkong and Kebongedang, Kiaracondong Bandung between January and March 2011. Children developmental screening was performed using kuesioner praskrining perkembangan (KPSP), or development pre-screening questionnaire, to show appropriate, suspected, or delayed interpretation. When the result of the questionnaire was not really clear for making conclusion, parents were tought to do the intervention at home every day for two weeks with a monitoring performed every 2 days using the daily card. If the result was still not clear after the intervention, the same intervention was repeated for 2 weeks under monitoring. The differences found in the pre and post design were analyzed with Cochran`s test. From 242 healthy children involved in this study, $208(86.0 \%)$ were categorized as appropriate, $33(13.6 \%)$ were suspected to experience developmental delay and one child $(0.4 \%)$ was delayed. One of thirty three children dropped out from this study because he was admitted to the hospital due to illness. After the intervention, the number of children who were suspected as experiencing delay decreased to $12 / 32$ in two weeks and to $4 / 32$ $(p<0.001)$ after the intervention ended. In conclusion, early intervention provides benefits to children aged 6-12 months who are suspected as experiencing developmental delay.[MKB. 2014;46(2):63-7]
\end{abstract}

Key words: Early detection, KPSP (development pre-screening questionnaire)

Korespondensi: Rumah Sakit Pusat Mata Cicendo Jalan Cicendo No.4 Bandung 40117, mobile 08122378929, e-mail susanty anne@yahoo.com 


\section{Pendahuluan}

Anak merupakan generasi penerus suatu bangsa sehingga diperlukan anak-anak yang berkualitas tinggi. Kualitas anak yang baik dapat diperoleh dari terpenuhinya kebutuhan aspek pertumbuhan dan perkembangan sehingga tercapai masa depan yang optimal. ${ }^{1-7}$ Untuk deteksi dini penyimpangan perkembangan maka sangat diperlukan penapisan perkembangan merupakan hal yang sangat penting dan sangat dianjurkan terhadap semua anak. ${ }^{8-}$ ${ }^{12}$ Di Amerika Serikat dilaporkan $12-16 \%$ anak balita dengan penyimpangan perkembangan. ${ }^{2,3,7}$ Kurang dari $30 \%$ anak yang dapat diidentifikasi penyimpangan perkembangan dan hanya sekitar 20-30\% penyimpangan dapat terdeteksi sebelum anak sekolah., 2,7, 10

Kuesioner praskrining perkembangan (KPSP) adalah alat yang dikeluarkan oleh Departemen Kesehatan bekerja sama dengan Ikatan Dokter Anak Indonesia (IDAI) tahun 2005. Kuesioner praskrining perkembangan itu berisi pertanyaan mengenai perkembangan yang sudah dicapai anak sesuai dengan usianya. Kuesioner tersebut dipilih karena penggunaannya mudah, cepat, dan dapat diterapkan di sarana kesehatan dasar. Hasil KPSP dikelompokkan: sesuai (skor 9 atau 10), meragukan (skor 7 atau 8), dan dicurigai penyimpangan (skor $\leq 6$ ). Apabila didapatkan hasil sesuai, orangtua tetap harus memberikan stimulasi pada anak di rumah dan pemeriksaan perkembangan rutin pada kunjungan berikutnya agar perkembangannya tetap sesuai menurut usia. Intervensi dilakukan bila hasil meragukan. Intervensi disarankan tiga kali sehari selama 1530 menit selama 2 minggu sehingga diharapkan perkembangan anak tersebut dapat menjadi sesuai menurut usia. ${ }^{11}$ Penelitian yang menggunakan alat KPSP di Indonesia telah dilakukan oleh Dhamayanti ${ }^{13}$ di Bandung pada bayi usia $15-18$ bulan dengan berat badan lahir normal, ditemukan $15 \%$ bayi dicurigai mengalami penyimpangan perkembangan.

Penelitian tentang manfaat intervensi dini di Indonesia masih belum banyak dilakukan sehingga dibutuhkan penelitian pada anak di sebuah wilayah tertentu agar dapat dilakukan pendekatan yang tepat. Tujuan penelitian ini untuk mengetahui manfaat intervensi dini anak usia $6-12$ bulan yang mengalami kecurigaan penyimpangan perkembangan.

\section{Metode}

Penelitian ini dilakukan selama bulan JanuariMaret 2011, di Kelurahan Cibangkong dan Kebongedang Kiaracondong, Bandung. Kriteria inklusi meliputi anak laki-laki dan perempuan usia 6-12 bulan yang sehat berdasarkan klinis dan kecurigaan penyimpangan perkembangan, sedangkan kriteria eksklusi meliputi riwayat persalinan prematur, asfiksia berat, dan terdapat kelainan kongenital. Subjek penelitian sebanyak 242 anak sehat usia 6-12 bulan. Penelitian ini dilakukan dengan metode tes pra dan pasca dengan komparatif kategorik berpasangan untuk menguji sebuah proporsi dan melihat apakah intervensi dini pada anak dengan kecurigaan penyimpangan perkembangan dapat bermanfaat. Dilakukan aloanamnesis terhadap orangtuanya, pemeriksaan fisis, dan penapisan perkembangan mempergunakan KPSP. Wawancara dilakukan terhadap orangtua mengenai riwayat persalinan sebelumnya dan hal yang telah dapat dilakukan anak di rumah.

Kuesioner praskrining perkembangan (KPSP) terdiri atas 10 dari setiap kelompok usia untuk mengetahui perkembangan yang telah dicapai anak. Pemeriksaan itu meliputi motorik kasar, motorik halus, bahasa, dan sosial.

Interpretasi hasil KPSP 7-8 yaitu anak dicurigai mengalami penyimpangan perkembangan pada satu atau lebih domain yang ada, dicurigai penyimpangan motorik kasar, motorik halus, bahasa, dan sosial. Intervensi dilakukan setiap hari oleh orangtua di rumah dengan menggunakan kartu harian dan dilakukan pemantauan dengan kunjungan rumah yang dilaksanakan oleh peneliti dan tenaga kesehatan setiap 2 (dua) hari untuk mengetahui apakah intervensi yang dilakukan sesuai. Untuk mengetahui manfaat intervensi dini anak usia 6-12 bulan dilakukan tes pre dan pasca, kemudian dilakukan analisis statistik Cochran dengan menggunakan SPSS 13.

\section{Hasil}

Selama periode penelitian diperiksa 242 anak sehat dan terdapat $208(86,0 \%)$ anak dengan perkembangan sesuai menurut usia, $33(13,6 \%)$ anak dengan hasil meragukan, dan $1(0,4 \%)$ anak penyimpangan. Satu orang anak dari 33 anak drop out karena dirawat di rumah sakit. Tabel 1 memperlihatkan karakteristik subjek dan orangtua dan didapatkan status gizi normal pada 29 anak (29/32). Tingkat pendidikan ayah dan ibu terbanyak adalah SMA. Hal ini dapat menjadikan dasar bahwa para orangtua, mengerti mengenai pentingnya perkembangan anak di kemudian hari. Pekerjaan ibu terbanyak adalah ibu rumah tangga (21/32) subjek.

Data lain menunjukkan hasil sebelum dan sesudah intervensi. Anak dengan kecurigaan penyimpangan perkembangan ditemukan pada 
Tabel 1 Karakteristik Subjek dan Orangtua

\begin{tabular}{|c|c|}
\hline Karakteristik & $\mathrm{n}=\mathbf{3 3}$ \\
\hline \multicolumn{2}{|l|}{ Jenis kelamin } \\
\hline Laki-laki & 19 \\
\hline Perempuan & 14 \\
\hline \multicolumn{2}{|l|}{ Status gizi } \\
\hline Underweight & 3 \\
\hline Normal & 29 \\
\hline Overweight & 1 \\
\hline \multicolumn{2}{|l|}{ Pendidikan ayah } \\
\hline SD & 2 \\
\hline SMP & 12 \\
\hline SMA & 14 \\
\hline Akademi/Perguruan Tinggi & 5 \\
\hline \multicolumn{2}{|l|}{ Pendidikan ibu } \\
\hline SD & 3 \\
\hline SMP & 13 \\
\hline SMA & 15 \\
\hline Akademi/Perguruan Tinggi & 2 \\
\hline \multicolumn{2}{|l|}{ Pekerjaan ayah } \\
\hline Buruh & 6 \\
\hline Swasta & 19 \\
\hline Wiraswasta & 8 \\
\hline \multicolumn{2}{|l|}{ Pekerjaan ibu } \\
\hline Ibu rumah tangga & 22 \\
\hline Bekerja & 11 \\
\hline
\end{tabular}

33 orang anak. Setelah intervensi yang dilakukan selama 2 minggu berkurang menjadi $12(12 / 32)$ orang anak. Anak yang masih terdapat kecurigaan penyimpangan perkembangan dilakukan kembali intervensi selama dua minggu dan didapatkan penurunan menjadi $4(4 / 32)$ orang anak. Terdapat hasil berbeda bermakna $(<0,001)$ menurut analisis Q Cochran setelah dilakukan intervensi pada anak dengan kecurigaan gangguan perkembangan.

Pada Tabel 2 dapat dilihat penyimpangan perkembangan sebelum dan sesudah dilakukan intervensiberdasarkanberbagai aspek. Kecurigaan terhadap 1 (satu) aspek kelainan perkembangan ditemukan pada motorik kasar dan motorik halus, sedangkan kelainan bahasa ditemukan pada kecurigaan kelainan perkembangan pada lebih dari satu aspek, misalnya kelainan perkembangan pada bahasa dan motorik kasar maupun bahasa dengan motorik halus. Terdapat 1 orang anak drop out saat dilakukan intervensi minggu pertama karena dirawat di rumah sakit sehingga analisis selanjutnya dilakukan pada 32 orang anak.

\section{Pembahasan}

Penelitian ini dilakukan pada anak usia 6-12 bulan karena pada usia 6 bulan kelahiran sampai sebelum menginjak usia 1 (satu) tahun kehidupan merupakan kesempatan emas untuk deteksi dini dan tindakan preventifnya, karena setelah tahap tersebut tidak banyak lagi yang dapat dikerjakan, kecuali mengupayakan berlangsungnya tumbuh kembang optimal. Hasil penelitian mendapatkan kecurigaan terjadi penyimpangan perkembangan pada anak, dan sesudah dilakukan intervensi berkurang bila dibandingkan dengan sebelumnya. Perkembangan anak merupakan hasil maturasi tubuh terutama susunan saraf pusat. Intervensi yang dapat dilakukan adalah melakukan tindakan koreksi dengan cara memanfaatkan plastisitas otak anak untuk dapat memperbaiki kecurigaan penyimpangan tumbuh kembang agar kembali normal atau kecurigaan penyimpangannya tidak semakin berat. ${ }^{14}$ Terdapat faktor perancu yang mungkin dapat memengaruhi hasil penelitian. Hal yang dapat menjadi faktor perancu adalah tingkat kepatuhan untuk melakukan intervensi dan frekuensi dilakukannya intervensi setiap hari di rumah.

Kecurigaan pada aspek perkembangan yang terganggu terdapat pada aspek motorik kasar dan motorik halus. Faktor yang dapat menyebabkan keterlambatan motorik yaitu kurangnya stimulasi, riwayat keluarga dengan perkembangan motorik yang terlambat, serta terdapat keadaan patologis seperti kelainan kongenital ataupun penyakit yang menyertai sebelumnya. ${ }^{8-10}$ Pada penelitian ini terdapat kecurigaan penyimpangan motorik pada 32 anak yang diperiksa baik motorik kasar maupun motorik halus. Kecurigaan penyimpangan motorik kasar sebanyak 2/32 subjek, sedangkan kecurigaan penyimpangan motorik halus $4 / 32$ subjek. Kombinasi terbanyak adalah kombinasi motorik kasar dan motorik halus, yaitu sebesar 10/32 subjek.

Kemampuan bahasa pada anak terbagi menjadi kemampuan bahasa reseptif dan bahasa ekspresif. Perkembangan bahasa tersebut merupakan aspek perkembangan yang sulit untuk dinilai karena anak terutama bayi tidak mengeluarkan suara saat diperiksa sehingga ketajaman anamnesis sangat diperlukan untuk mendapatkan riwayat perkembangan bahasa. Kemampuan bahasa itu dapat menjadi indikator seluruh perkembangan anak. Kemampuan bahasa itu sensitif terhadap keterlambatan ataupun kerusakan pada sistem lainnya, karena melibatkan kemampuan kognitif, motor, psikologis, emosi, dan lingkungan sekitar 
Tabel 2 Tabel Kecurigaan Penyimpangan Perkembangan Sebelum dan Setelah Intervensi

\begin{tabular}{|c|c|c|c|c|}
\hline \multirow{2}{*}{$\begin{array}{l}\text { Kecurigaan } \\
\text { penyimpangan } \\
\text { Perkembangan }\end{array}$} & $\begin{array}{c}\text { Sebelum } \\
\text { Intervensi } \\
(n=33)\end{array}$ & $\begin{array}{c}\text { Intervensi } I \\
(\mathbf{n}=\mathbf{3 2})\end{array}$ & $\underset{(\mathbf{n}=12)}{\text { Intervensi }}$ & $\begin{array}{c}\text { Setelah Intervens } \\
\qquad(\mathrm{n}=4)\end{array}$ \\
\hline & \multicolumn{4}{|c|}{ Jumlah } \\
\hline \multicolumn{5}{|l|}{ Aspek } \\
\hline Motorik kasar & 2 & 2 & 0 & 0 \\
\hline Motorik halus & 4 & 3 & 1 & 1 \\
\hline Bahasa & 0 & 0 & 0 & 0 \\
\hline Sosial & 0 & 0 & 0 & 0 \\
\hline \multicolumn{5}{|l|}{ Kombinasi } \\
\hline 1 dan 2 & 10 & 10 & 3 & 1 \\
\hline 1 dan 3 & 2 & 2 & 2 & 0 \\
\hline 1 dan 4 & 1 & 1 & 0 & 0 \\
\hline 2 dan 3 & 7 & 7 & 0 & 0 \\
\hline 2 dan 4 & 0 & 0 & 0 & 0 \\
\hline 3 dan 4 & 0 & 0 & 0 & 0 \\
\hline Lebih dari 2 & 7 & 7 & 6 & 2 \\
\hline
\end{tabular}

anak. ${ }^{11,13,15}$ Pada penelitian ini aspek bahasa yang terganggu tidak berdiri sendiri tetapi disertai dengan kecurigaan penyimpangan motorik, yaitu motorik halus hingga mencapai $7 / 32$ subjek. Hal ini dapat terjadi karena dalam upaya memberikan rangsangan terhadap anak mengenai motorik halus yang dilakukan, ibu atau pengasuh sebaiknya menggunakan pula bahasa verbal agar anak dapat dengan lebih mudah mengerti dan mengikuti apa yang diajarkan orangtua. Kontak sosial dan komunikasi nonverbal termasuk vokalisasi dan juga tingkah laku akan dapat membangun komunikasi anak. Kurangnya stimulasi dapat menyebabkan kecurigaan penyimpangan bicara dan berbahasa. ${ }^{4}$ Kontak sosial dan komunikasi nonverbal termasuk vokalisasi dan tingkah laku akan dapat membangun komunikasi anak. ${ }^{1}$ Pada penelitian ini aspek bahasa lebih sulit untuk dilakukan intervensi dibandingkan dengan aspek lainnya. Diperlukan waktu dua kali intervensi, yaitu selama 1 bulan untuk mengatasi kecurigaan penyimpangan bahasa.

Pada bayi perkembangan personal sosial lebih sulit untuk diketahui. Hal ini disebabkan oleh perhatian bayi yang mudah teralihkan. Interaksi sosial akan timbul pertama kali saat anak di rumah karena rumah merupakan tempat pertama anak berinteraksi dengan ibu. Interaksi ini dapat dilakukan oleh ibu sendiri, anggota keluarga lainnya maupun pengasuh anak. Interaksi yang dapat ditanyakan kepada orangtua di rumah berdasarkan kemampuan anak terhadap interaksi sosial menurut usia, misalnya apakah anak dapat mudah menengok ketika dipanggil, mendengar dengan baik, serta dapat berinteraksi dengan ibu ataupun pengasuh. ${ }^{11,13,15}$

Penelitian terdahulu yang menggunakan alat KPSP di Indonesia dilakukan oleh Dhamayanti ${ }^{13}$ di Bandung pada bayi usia 15-18 bulan dengan berat badan lahir normal. Pada penelitiannya ditemukan $15 \%$ bayi itu mengalami kecurigaan penyimpangan perkembangan. Sensitivitas dan spesifisitas KPSP adalah $60 \%$ dan $92 \%$.

Anak yang sudah sesuai perkembangannya menurut usia tetap membutuhkan stimulasi untuk perkembangan selanjutnya. Stimulasi diberikan dengan memperhatikan kebutuhan anak sesuai dengan tahapan perkembangan. Stimulasi verbal pada tahun pertama kehidupan penting untuk perkembangan bahasa anak. ${ }^{11}$

Intervensi ke-2 dilakukan pada 12 orang anak yangsebelumnyatelah dilakukanintervensiselama 2 minggu di rumah dan masih mendapatkan hasil yang meragukan pada KPSP. Stimulasi tumbuh kembang anak dilakukan oleh ibu dan ayah yang merupakan orang terdekat anak, pengganti $\mathrm{ibu/pengasuh} \mathrm{anak,} \mathrm{atau} \mathrm{anggota} \mathrm{keluarga} \mathrm{lain.}$ Peserta penelitian sebagian besar, yaitu 21/32 subjek diasuh oleh ibunya sendiri tetapi sisanya diasuh oleh pengasuh ataupun anggota keluarga yang lain. Terdapat hal yang menyulitkan saat dilakukannya intervensi itu, yaitu penyediaan waktu oleh ibu karena ibu bekerja mempunyai waktu yang lebih sedikit dibandingkan dengan 
ibu rumah tangga, anggota keluarga lainnya maupun pengasuh setiap harinya untuk melatih anak, tingkat kepatuhan untuk dapat melakukan intervensi serta kesadaran orangtua mengenai pentingnya dilaksanakan intervensi bagi anak dengan kemungkinan kecurigaan penyimpangan perkembangan. Hal ini berpengaruh terhadap frekuensi dan kualitas waktu yang diberikan untuk melakukan intervensi terhadap anak. ${ }^{4}$

Bermain dan mengajak berbicara (komunikasi verbal) merupakan hal yang sangat dianjurkan karena bermain, bukan hanya mengisi waktu luang tetapi diharapkan anak dapat turut serta mengoordinasikan dan juga mengendalikan ototototnya. ${ }^{13}$ Pekerjaan sebagai ibu rumah tangga sering kali mempersulit kelancaran intervensi karena sangat berhubungan dengan pola asuh sehingga anak lebih sering digendong saat ibu menyelesaikan seluruh pekerjaan rumah. Hal ini merupakan salah satu faktor yang dapat menjadi penyebab keterlambatan kegiatan proses intervensi perkembangan anak. ${ }^{13}$

Intervensi selama 1 (satu) bulan pada anak dengan kecurigaan penyimpangan perkembangan terbukti cukup efektif bila dibandingkan dengan intervensi yang dilakukan selama 2 (dua) minggu.

Keterbatasan penelitian ini yaitu jumlah subjek yang terbatas, waktu penelitian yang singkat, dan kesulitan melakukan intervensi bila anak sedang dalam keadaan tidur pada saat kunjungan rumah. Perbaikan perkembangan anak pada penelitian ini sebaiknya dilakukan kembali dengan jumlah anak yang lebih besar dan perlu grup kontrol.

Simpulan penelitian ini, yaitu terdapat manfaat intervensi dini yang dilakukan selama satu bulan pada anak usia 6-12 bulan yang mengalami kecurigaan penyimpangan perkembangan.

\section{Daftar Pustaka}

1. Council on Children With Disabilities, Bright Futures Steering Committee and Medical Home Initiatives for Children With Special Needs Project Advisory Commitee. Identifying infants and young children with developmental disorders in the medical home: an algorithm for developmental surveillance and screening. Pediatrics. 2006;118:405-20.

2. Drotar D, Stancin T, Dworkin PH, Sices L. Selecting developmental surveillance and screening tools. Pediatr Rev. 2008;29:e52-8.

3. American Academy of Pediatrics. Developmental surveillance and screening of infant and young children. Pediatrics. 2001;108:192-6.

4. Winter S. Developmental screening and surveillance. Pediatrics. 2007;5(3):2-6.

5. Dworkin PH. Developmental screening: (still) expecting the impossible? Pediatrics. 1992;89:1253-5.

6. Wijnhoven T, Onis MD, Onyango AW, Wang T, Bjoerneboe GE. Assessment of gross motor development in the WHO multicenter growth reference study. Food Nutr Bull. 2004;25:37-46.

7. Sand N, Silverstain M, Glascoe FP, Gupta VB, Tonniges TP, O`Connor KG. Pediatricians reported practices regarding developmental screening: do guidelines work?do they help? Pediatrics. 2005;116:174-9.

8. Petersen MC, Kube DA, Whitaker TM, Graff JC. Prevalence of developmental and behaviour disorders in a pediatric hospital. Pediatrics. 2009;123:e490-5.

9. Baker H, Lopez F. Early childhood stimulation interventions in developing countries: a comprehensive literature review [diunduh 5 Desember 2010]. Tersedia dari: http://idbdocs.iadb.org/wsdocs/getdocument. aspx?

10. Fadlyana E. Keterlambatan perkembangan balita di daerah pedesaan dan perkotaan Bandung dan sekitarnya serta faktor-faktor yang mempengaruhinya. Sari Pediatri. 2003; 5(2):168-75.

11. Departemen Kesehatan Repubrik Indonesia. Pedoman pelaksanaan stimulasi, deteksi dan intervensi dini tumbuh kembang anak di tingkat pelayanan dasar. Jakarta: Departemen Kesehatan Repubrik Indonesia; 2005.

12. Tanuwidjaja S. Konsep tumbuh kembang anak. Dalam: Narendra M, Sularyo, Soetjiningsih, penyunting. Tumbuh kembang anak dan remaja. Edisi ke-1. Jakarta: Sagung Seto; 2002. hlm. 1-2.

13. Dhamayanti M. Kuesioner pra skrining perkembangan anak. Sari Pediatri. 2006; $8(2): 9-15$.

14. Soetjiningsih. Tumbuh kembang anak. Edisi ke-1. Jakarta: Buku Kedokteran EGC; 1995.

15. Soetjiningsih. Perkembangan anak dan permasalahannya. Dalam: Narendra MB, Sularyo TS, Soetjiningsih, Sularyo TS, Ranuh G, penyunting. Tumbuh kembang anak dan remaja. Edisi ke-1. Jakarta: Sagung Seto; 2002. hlm. 186-93. 